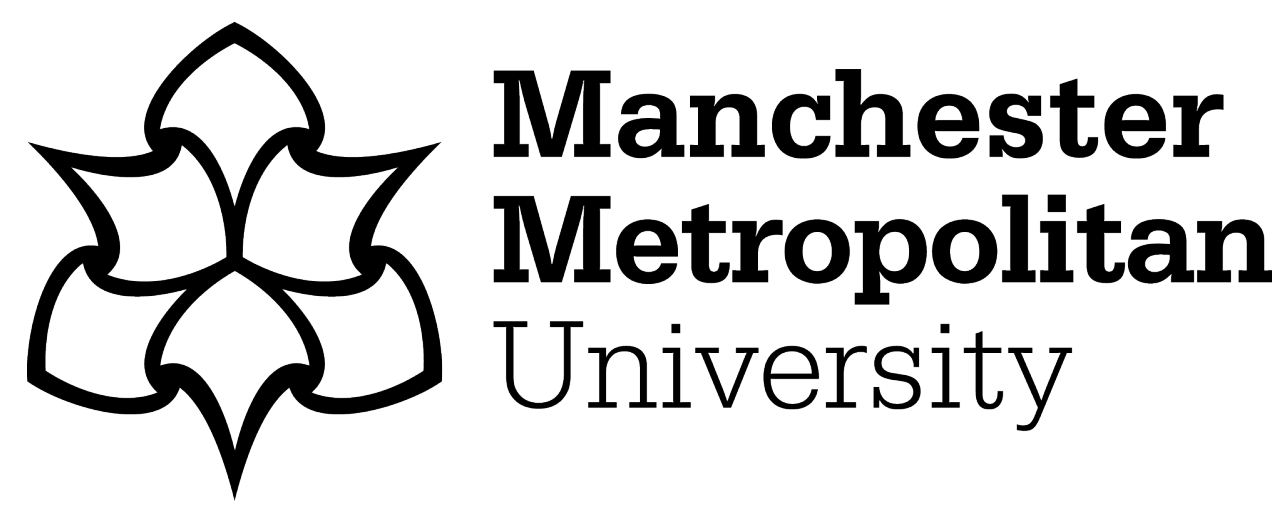

Batunlu, C and Albarbar, A ORCID logoORCID: https://orcid.org/0000-00031484-8224 (2016) Real-time system for monitoring the electro-thermal behaviour of power electronic devices used in boost converters. Microelectronics Reliability, 62. pp. 82-90. ISSN 0026-2714

Downloaded from: https://e-space.mmu.ac.uk/43/

Version: Accepted Version

Publisher: Elsevier

DOI: https://doi.org/10.1016/j.microrel.2016.03.033

Please cite the published version 


\title{
Real-Time System for Monitoring the Electro-Thermal Behaviour of Power Electronic Devices used in Boost Converters
}

\author{
C. Batunlu, A. Albarbar \\ Engineering and Materials Research Centre, \\ Power, Renewable and Sustainability Research Group \\ School of Engineering \\ Manchester Metropolitan University \\ Manchester, United Kingdom \\ e-mail:canras.batunlu@stu.mmu.ac.uk, a.albarbar@mmu.ac.uk
}

\begin{abstract}
Reliability of power electronic devices (PEDs) is a key issue to secure power supplies in modern word, especially, those generated from renewable energy sources. Thermal stress due to switching frequency and environmental conditions are commonest cause of currently unsatisfactory PEDs reliability scores.

In this paper, the electro thermal performance of PEDs and related parameters are critically investigated using three types of differently manufactured insulated gate bipolar transistors (IGBTs). Namely, punch through (PT), non-punch through (NPT) and field stop (FS) silicon trench gate technologies.

First, currents and voltages of the examined IGBTs were measured under different operating temperatures, switching frequencies and electrical loading conditions.

Second, power losses of the examined devices were calculated, in real time, based on their measured currents and voltages using realistic mathematical model embedded in a dSPACE system. Subsequently, the power losses for each device were used as an input to a finite element model to graphically predict heat distributions for each of the monitored devices.

Compared to expensive measurements taken by high-resolution thermal imaging cameras, the accuracy of the developed system achieved $97 \%$. The obtained results demonstrate the developed model would serve as an inexpensive and powerful tool for monitoring PEDs thermal conditions.
\end{abstract}

Keywords- power electronic devices, IGBT, electro thermal behaviour, boost converter, DSPACE, thermal imaging

\section{INTRODUCTION}

Increased demand for power electronic converters (PECs) especially in renewable energy applications has necessitated deeper investigation into the reliability of such systems. Insulated gate bipolar transistors (IGBTs) are widely used as switching devices for PECs. IGBTs serve as switching elements where temperature cycling causes thermal stress and eventual failures. Hence, accurate electro thermal modelling, temperature monitoring and control are essential to estimate and extend the life cycle of PECs. Latest manufacturing technologies of IGBTs have led to thinner silicon- and trench-gated devices [1]. To overcome the downsides of the planar gate devices such as punch-through (PT) and Non-Punch-Through (NPT), vertical, trench gate 
Please cite this article as: C. Batunlu, A. Albarbar, Real-time system for monitoring the electro-thermal behaviour of power electronic devices used in boost converters, Microelectronics Reliability (2016), http://dx.doi.org/10.1016/j.microrel.2016.03.033

technology has been developed. Charge injection enhancement, reduced tail current at turn off and decreased power loss profiles were achieved by this technology. Further improvements such as faster switching capability and higher current density, attained with Field Stop (FS) emerging technology which is constructed by field-stop region added to thin-wafer NPT device. Figure 1 shows the physical differences among these three trench gate structured IGBTs.

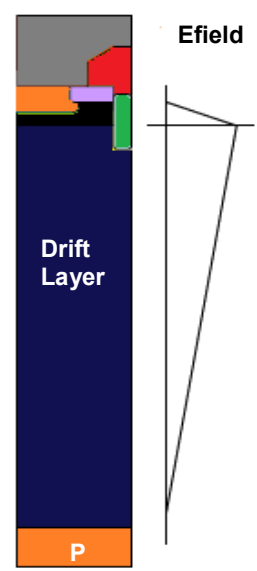

(a)

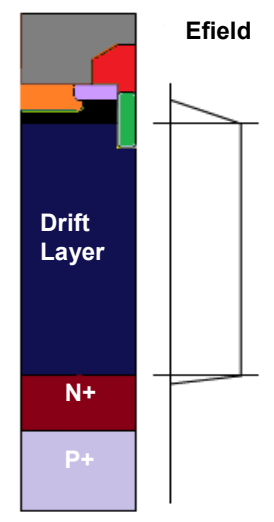

(b)

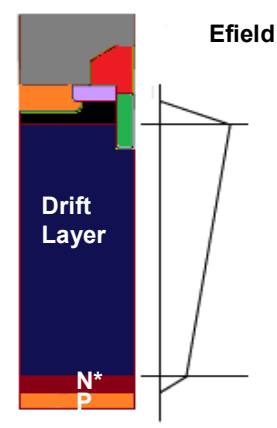

(c)

Figure 1: (a) Trench NPT, (b) Trench PT and (c) Trench FS IGBTs

In literature, Chibante et al. studied physics based models for NPT [2] and PT IGBTs [3] for hole/electron distribution based on ambipolar diffusion equation. Takaishi et al. [4] studied analytical formulation turn-off waveform for advanced trench gate IGBTs for calculating tradeoff curve between turn-off loss and saturation voltage. Ronsisvalle et al. [5] proposed an experimental characterization for the input capacitance of FS Trench IGBTs.

In contrast, accurate electro thermal modelling and temperature monitoring of IGBT's depends on collector tail current and collector to emitter saturation voltage. Thus, power sensing elements have to be coupled within electro thermal models accurately. Electro thermal models consist of power loss and thermal models, which can continuously monitor temperature variation for power electronic devices. Power losses occur due to the rapid changes in current and voltage ratings leading to thermal flux through those devices. Since the energy losses are accepted as the main cause of the heat generation through power semiconductor devices [6], modelling power losses of those power system elements is essential for determining their electro thermal behaviour. Tang et al. [7] proposed FS switching transient model for simulating the turn-off tail current switching transient of IGBT at different temperatures. It was analysed that base excess carrier lifetime has a great influence on the temperature characteristics of 
Please cite this article as: C. Batunlu, A. Albarbar, Real-time system for monitoring the electro-thermal behaviour of power electronic devices used in boost converters, Microelectronics Reliability (2016),

http://dx.doi.org/10.1016/j.microrel.2016.03.033

switching transient and thermal behaviour greatly changes during on and off times. Dynamic avalanche on PT IGBTs to locate active areas of chip region and thermal analysis using FE simulations studied by Lefranc et al. [8]. Yet, parasitic elements of IGBTs such as carrier mobility, excitation concentration and transconductance vary with temperature [7]. Hence the performance of IGBTs in terms of on-state voltage, tail current, switching speed and lifetime are affected [9]. Many studies present FE models of power modules for thermal impedance characterization and derive thermal models based on the generic current signals. In fact, limited amount of data is supplied by the manufacturer datasheets for the switching characteristic although the listed properties above are temperature depended. This can cause vital changes in the electro thermal performance of IGBTS based on the application type they are used [10]. For instance, DC-DC boost converters are widely used in a number of applications [11]. A reliability study presented by Khosroshahi et al. [12] showed that IGBT technology used and operating modes of the converter matter on overall life time. For accurate electro thermal modelling, Blinov et al. [13] investigated ways on improving the calculation of conventional power loss based on manufacturers' datasheet information. Energy losses were calculated with respect to the sample current-voltage input characteristics. Similar model was proposed by Rui et al. [14] with the extension of temperature and on time resistance dependent electro thermal models. The simulation was executed with PSCAD software and 1.4\% loss rating is estimated compared to analytical calculations. Similar approach, presented by Ivakhno et al. [15], was carried out using logic blocks in Simulink. Power loss calculation was achieved based on the output current and voltage signals of IGBT/Diode block element and coupled within thermal models. Zhou et al. [16] studied another time-domain electro thermal model which was extended by other authors $[17,18]$. Look up table based power loss calculations were integrated with thermal models for electro thermal monitoring of multilevel converter power electronic devices. Pittini et al. [19] developed electro thermal model for two level converter using PSCAD block sets to determine thermal and energy losses using parameters extracted from device's datasheet. Kim et al. [20] stated power losses are highly depend on the operating temperature and current signal characteristics at different operating conditions. Hence, analytical electro thermal calculations with generic signals can show significant inaccuracies. In this study, voltage and current data are collected from three boost converter sets (designed with different IGBTs) and stored into dSPACE system where a carefully derived mathematical electro thermal model was embedded to predict temperatures and power losses in the tested 
Please cite this article as: C. Batunlu, A. Albarbar, Real-time system for monitoring the electro-thermal behaviour of power electronic devices used in boost converters, Microelectronics Reliability (2016), http://dx.doi.org/10.1016/j.microrel.2016.03.033

devices. The developed system used actual boost converters operated under different conditions and processed the measured voltage and current in dSPACE. The predicted power losses are subsequently used by the FE model (derived in COMSOL) to estimate and graphically display heat distributions for the tested devices.

The paper is structured as follows: in Section 2, methodology and experimental setup are outlined. The mathematical and electro thermal models (in Simulink and COMSOL) for the tested IGBTs are described in Section 3. Results and comments on theoretical and experimental investigations are presented in Section 4. Conclusions are depicted in the final section.

\section{METHODOLOGY AND EXPERIMENTAL SETUP}

\subsection{Methodology}

The developed methodology flowchart and the experimental setup in this study are shown in Figure 2 and Figure 3, respectively.

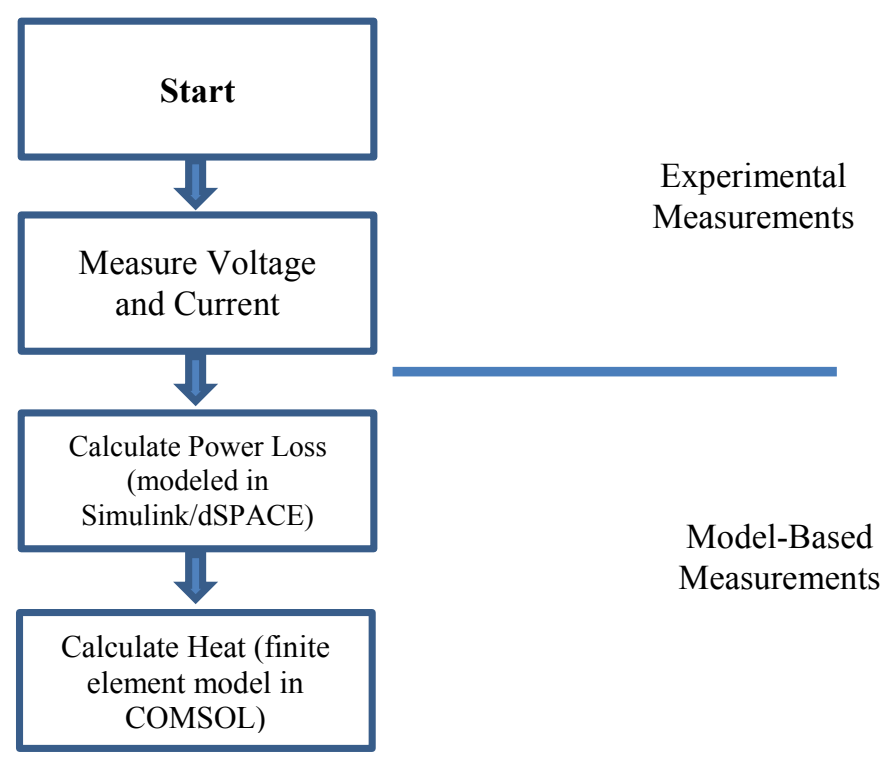

Figure 2: Flowchart of the proposed system

All of the tested IGBTs were initially supplied by a constant gate signal and $5 \mathrm{~V}$ collectoremitter voltages under constant loads until steady state temperatures. Current and voltage measurements were taken, in addition to temperatures every 5 seconds, taken by high-resolution thermal camera (FLIR T440) [21]. The thermal impedance was intentionally represented by three exponential terms in order to increase the computational speed and they were extracted by curve fitting using the least square method. 
Please cite this article as: C. Batunlu, A. Albarbar, Real-time system for monitoring the electro-thermal behaviour of power electronic devices used in boost converters, Microelectronics Reliability (2016), http://dx.doi.org/10.1016/j.microrel.2016.03.033

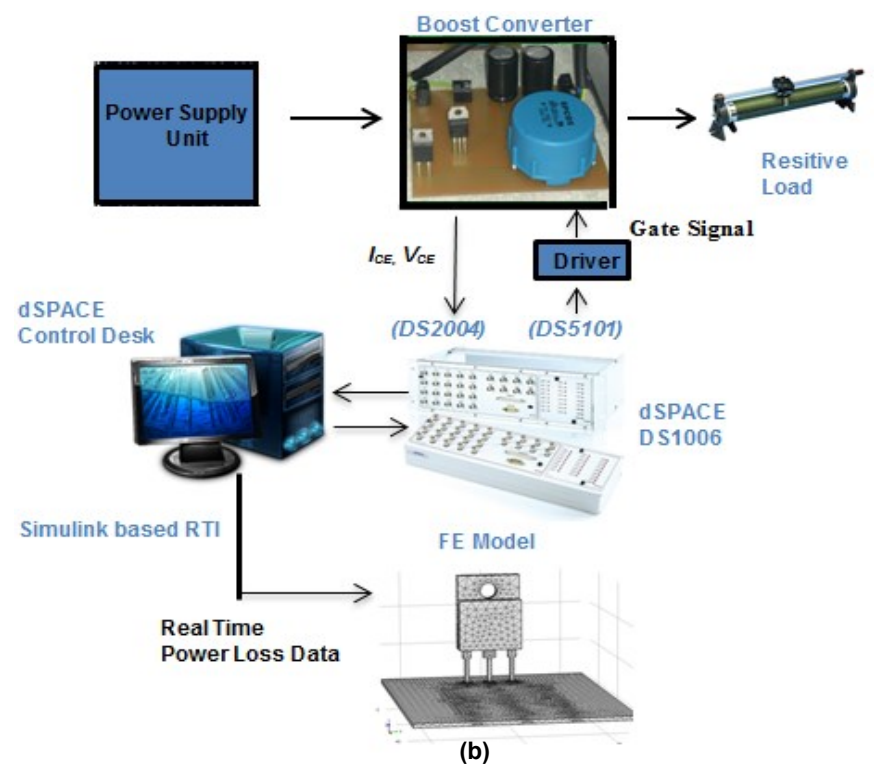

Figure 3: Schematic diagram of the proposed system

Devices thermal resistances $R_{t h}$ and capacitances $C_{t h}$ were determined using Eqn. 1

$$
T_{m}(s)=\sum_{k=1}^{N} \frac{1 / \mathrm{Cth}_{n}}{s+1 /\left(\mathrm{Cth}_{\mathrm{n}} \cdot \operatorname{Rth}_{\mathrm{n}}\right)} P_{n}(s)
$$

where $T$ represents temperature and $P$ is the power loss. The model, built in Simulink, was based on thermal Foster network shown in Figure 4.

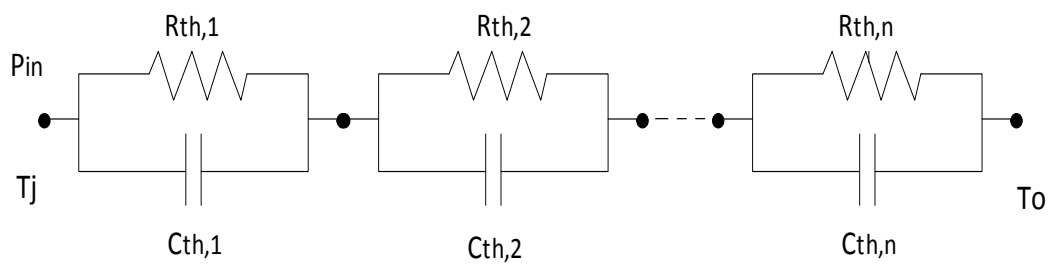

Figure 4: Foster thermal network

The calculated thermal resistances and capacitances are shown in Table 1. Measured currents and voltages in addition to calculated thermal resistances and capacitances are interfaced to the real-time electro-thermal monitoring scheme (in dSPACE) depicted in Figure 5.

Table 1: Interpolated thermal characteristic

\begin{tabular}{|c|c|c|c|c|c|c|}
\hline \multirow{2}{*}{ Tested Device } & \multicolumn{3}{|c|}{ Thermal Capacitance } & \multicolumn{3}{c|}{ Thermal Resistance } \\
\cline { 2 - 7 } & $\boldsymbol{C}_{\boldsymbol{t h}, \boldsymbol{l}}$ & $\boldsymbol{C}_{\boldsymbol{t} \boldsymbol{h}, \boldsymbol{2}}$ & $\boldsymbol{C}_{\boldsymbol{t h}, \mathbf{3}}$ & $\boldsymbol{R}_{\boldsymbol{t h}, \boldsymbol{l}}$ & $\boldsymbol{R}_{\boldsymbol{t} \boldsymbol{h}, \boldsymbol{2}}$ & $\boldsymbol{R}_{\boldsymbol{t} \boldsymbol{h}, \boldsymbol{3}}$ \\
\hline FS & 0.22 & 0.02 & 0.0013 & 0.2911 & 0.409 & 0.5008 \\
\hline PT & 0.24 & 0.015 & 0.019 & 0.282 & 0.35 & 0.502 \\
\hline NPT & 0.28 & 0.018 & 0.0014 & 0.2811 & 0.4 & 0.5019 \\
\hline
\end{tabular}

The dSPACE blocks are shown in Figure 5, two (DS2004ADC) blocks are used for current and voltage readings and three (DS5101PWMDAC) for providing gate signals to each IGBT used

Please cite this article as: C. Batunlu, A. Albarbar, Real-time system for monitoring the electro-thermal 
Please cite this article as: C. Batunlu, A. Albarbar, Real-time system for monitoring the electro-thermal behaviour of power electronic devices used in boost converters, Microelectronics Reliability (2016), http://dx.doi.org/10.1016/j.microrel.2016.03.033

in boost converters. DS $2004 \mathrm{~A} / \mathrm{D}$ platform of dSPACE uses 5V gain for protection purpose. Hence the first constant is to acquire the gain caused by the $\mathrm{A} / \mathrm{D}$ platform itself. The collector current signals were monitored by hall-effect based ACS712 linear current sensors. The sensor has $2.5 \mathrm{~V}$ of threshold value. This is acquired by the second additional constant in the model. The sensor also has an $185 \mathrm{mV} / \mathrm{A}$ sensitivity which was then acquired by the gain block of 0.0185. The final constant is to acquire the threshold on the dSPACE Control Desk. A zoomed in view of power loss calculation blocks are illustrated in Figure 6. The output temperatures then fed back into power loss model along with the voltage and current signals for continuous monitoring of the electro thermal behaviour of the IGBT. Three tests were carried out to assess the performance of the IGBTs, namely operation under different ambient temperatures, different switching frequencies and finally, when operated under different electrical loading. All tests took place simultaneously and under same conditions to ensure repeatability and confidence of measurements.

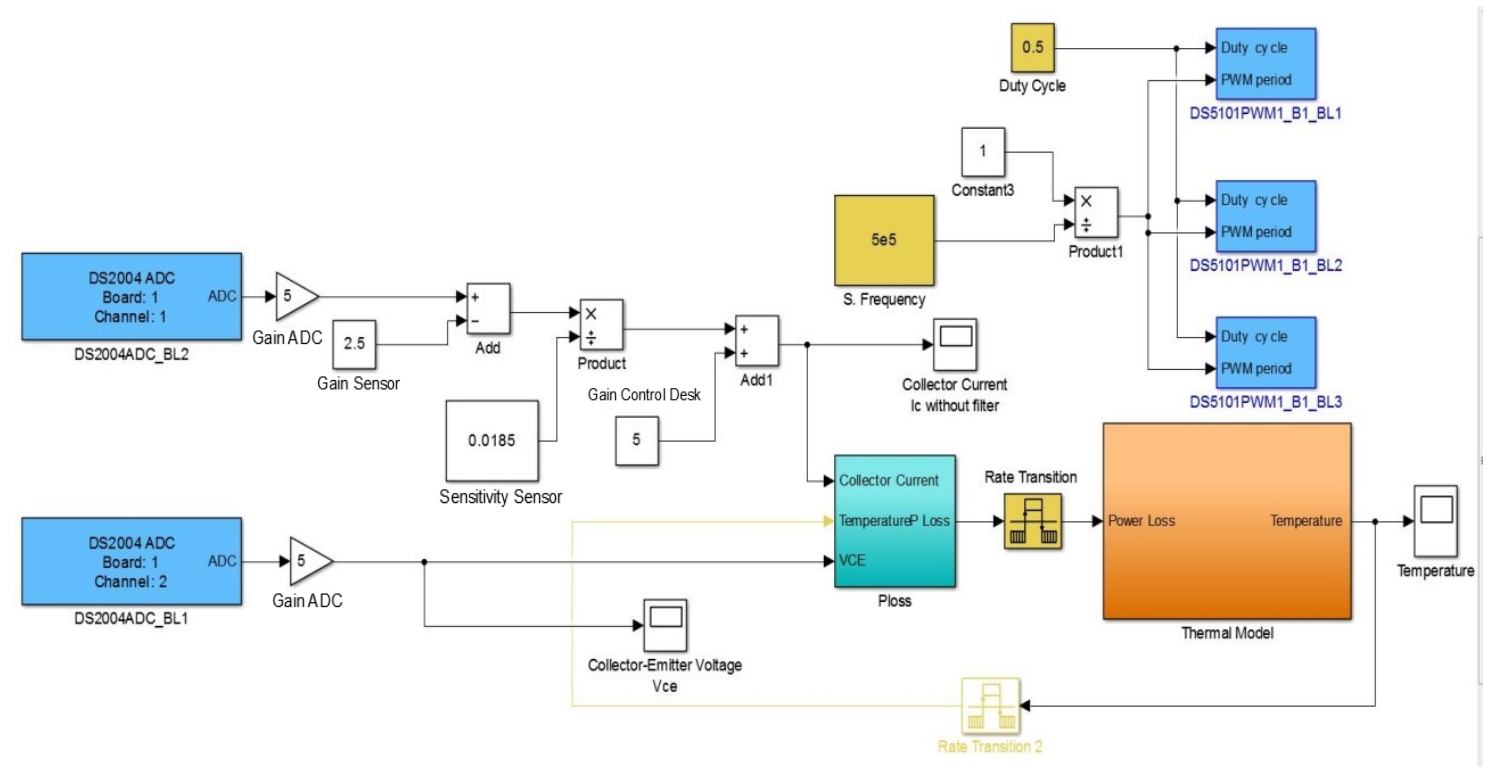

Figure 5: Real-time implementation of electro thermal model in DSAPCE

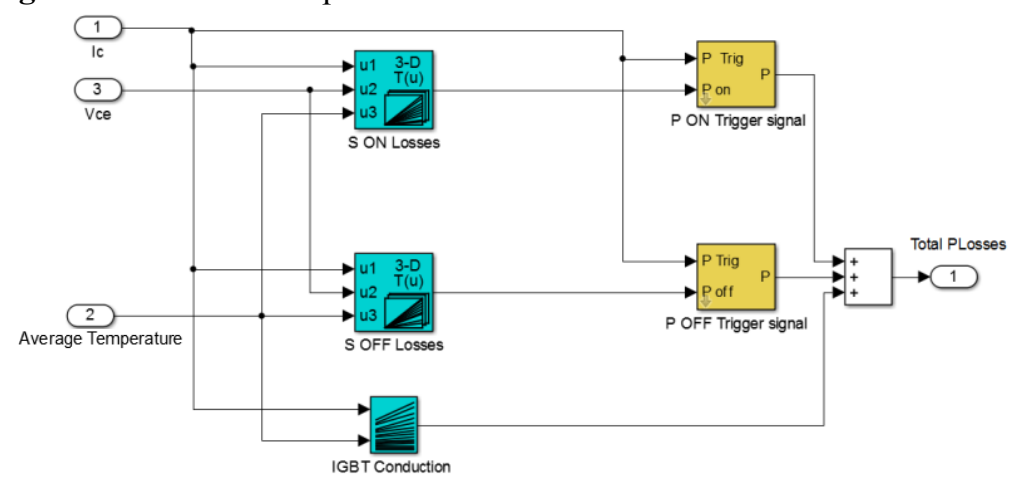

Figure 6: View of the power loss block in dSPACE

Please cite this article as: C. Batunlu, A. Albarbar, Real-time system for monitoring the electro-thermal behaviour of power electronic devices used in boost converters, Microelectronics Reliability (2016), http://dx.doi.org/10.1016/j.microrel.2016.03.033 
Please cite this article as: C. Batunlu, A. Albarbar, Real-time system for monitoring the electro-thermal behaviour of power electronic devices used in boost converters, Microelectronics Reliability (2016), http://dx.doi.org/10.1016/j.microrel.2016.03.033

\subsection{1: Effects of Ambient Temperature:}

All units were operated under same conditions and ambient temperature was increased in steps of $5^{\circ} \mathrm{C}$ up to $50^{\circ} \mathrm{C}$ starting from room temperature of $25^{\circ} \mathrm{C}$. Junction temperature of each IGBT was accurately identified, at each ambient temperature when reached steady state, using thermal imaging camera.

\subsection{2: Effects of Switching Frequency:}

Tested devices were driven, simultaneously, by four sets of different switching frequency. Heat sinks were used in those tests with a current of $5 \mathrm{~A}$.

\subsection{3: Effects of Load Variation:}

In this test, the devices were examined under different loading conditions. The ambient temperature and switching frequency were kept constant to $30^{\circ} \mathrm{C}$ and $20 \mathrm{kHz}$ respectively. Loading was varied from zero to full load in steps of $20 \%$.

\subsection{Experimental Setup}

Three sets of boost converter units, shown in Figure 7, were implemented using three different types of IGBTs (namely, A, B and C), with specification presented in Table 2.

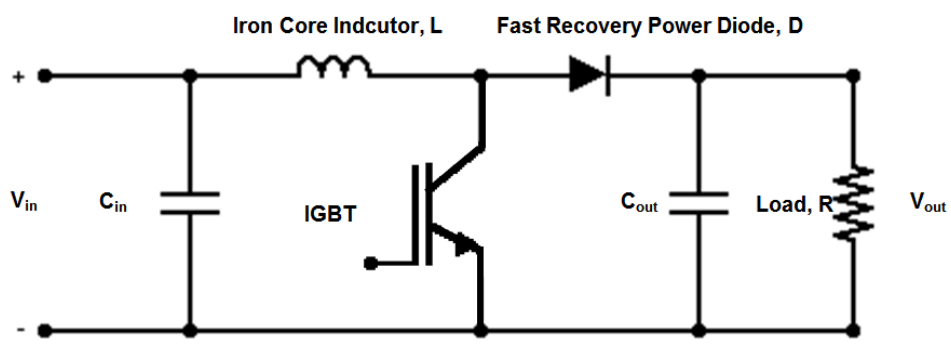

Figure 7: Boost Converter Circuitry

Table 2: Characteristics IGBTs A, B and C

\begin{tabular}{|c|c|c|c|c|}
\hline & IGBT (A) & IGBT (B) & IGBT (C) & Unit \\
\hline Specification & NPT-Si & PT-Si & FS-Si & - \\
\hline Price & $£ 1.00$ & $£ 1.2$ & $£ 1.19$ & \\
\hline$V_{\text {CEs }}$ & 600 & 600 & 600 & $\mathrm{~V}$ \\
\hline Gate & Trench & Trench & Trench & \\
\hline$I_{C}(\mathrm{~T}=\mathbf{2 5 C})$ & 25 & 25 & 20 & $\mathrm{~A}$ \\
\hline$I_{C}(T=100 C)$ & 15 & 14 & 10 & A \\
\hline$\left.V_{\text {CEsat,typ }(T=25 C, I c=m a x}\right)$ & 1.75 & 2 & 1.5 & $\mathrm{~V}$ \\
\hline$V_{\text {CEsat, } \max }(\mathrm{T}=25 \mathrm{C}, \mathrm{Ic}=\max )$ & 1.95 & 2.5 & 2.05 & $\mathrm{~V}$ \\
\hline $\mathrm{C}_{\text {ies }}$ & 1950 & 760 & 551 & $\mathrm{pF}$ \\
\hline $\mathrm{C}_{\text {oes }}$ & 70 & 86 & 40 & $\mathrm{pF}$ \\
\hline $\mathrm{C}_{\text {res }}$ & 42 & 15.5 & 17 & $\mathrm{pF}$ \\
\hline $\mathbf{Q g}_{\mathrm{g}}$ & 88 & 34.4 & 62 & $\mathrm{nC}$ \\
\hline $\operatorname{td}(o n)(T=25 C)$ & 65 & 22.5 & 12 & ns \\
\hline
\end{tabular}


Please cite this article as: C. Batunlu, A. Albarbar, Real-time system for monitoring the electro-thermal behaviour of power electronic devices used in boost converters, Microelectronics Reliability (2016), http://dx.doi.org/10.1016/j.microrel.2016.03.033

\begin{tabular}{|c|c|c|c|c|}
\hline $\mathbf{t}_{\mathbf{r}}$ & 28 & 8.5 & 8 & $\mathrm{~ns}$ \\
\hline $\mathbf{t}_{\mathbf{d}(\mathbf{o f f})}$ & 170 & 116 & 215 & $\mathrm{~ns}$ \\
\hline $\mathbf{t}_{\mathbf{f}}$ & 140 & 75 & 38 & $\mathrm{~ns}$ \\
\hline $\mathbf{E}_{\mathbf{o n}(\mathbf{T}=\mathbf{2 5 C})}$ & 0.55 & 0.082 & 0.16 & $\mathrm{~mJ}$ \\
\hline $\mathbf{E}_{\mathbf{o f f}(\mathbf{T}=\mathbf{2 5 C})}$ & 0.350 & 0.155 & 0.27 & $\mathrm{~mJ}$ \\
\hline $\mathbf{P}_{\text {loss(T=25C) }}$ & 117 & 112 & 110 & $\mathrm{~W}$ \\
\hline $\mathbf{P}_{\text {loss(T=100C) }}$ & 47 & - & - & $\mathrm{W}$ \\
\hline
\end{tabular}

A physical photo of the experimental setup and equipment are shown in Figure 8.

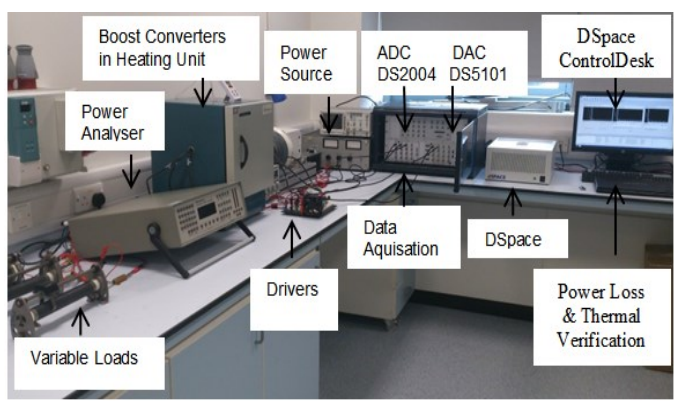

(a)

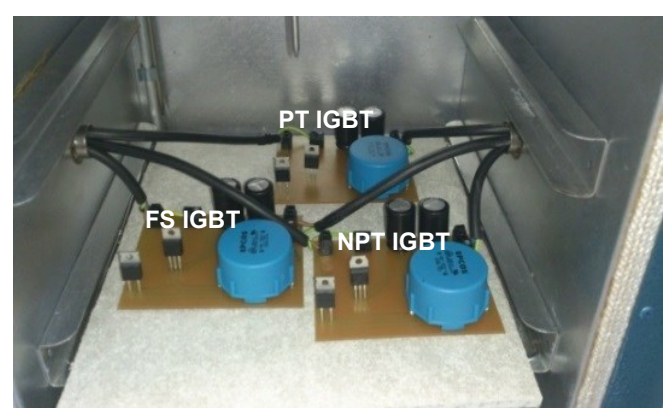

(b)

Figure 8: (a) Experimental setup, (b) boost converters in temperature controlled chamber

\section{FINITE ELEMENT MODELLING AND NUMERICAL SIMULATION}

A 3-D finite element IGBT model was derived using COMSOL Multiphysics modelling software. The heat distribution through each material was determined using Eqn. 2:

$$
\frac{\partial^{2} T}{\partial x^{2}}+\frac{\partial^{2} T}{\partial y^{2}}+\frac{\partial^{2} T}{\partial z^{2}}+\frac{q}{k}=\frac{\rho . c}{k} \frac{\partial T}{\partial t}
$$

where $T$ is the temperature, $k$ is the thermal conductivity, $c$ is specific heat capacity, $\rho$ is the mass density and $q$ is the rate of generation of energy per unit volume. Material properties such as conductivity and coefficient of thermal expansion are temperature dependent. View of the meshed FE model for TO-220 package and the region for the applied real time power loss profile can be seen in Figure 9 a and b, respectively. The collector pin is directly attached to the case. The gate and emitter on the other hand are connected to wire bonds. Chip areas can also be seen in Figure 9(b) for each IGBT technology.

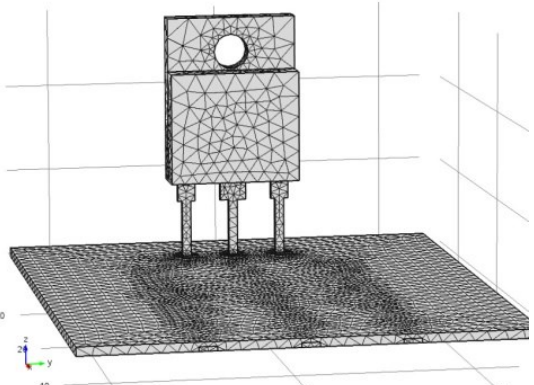

(a)

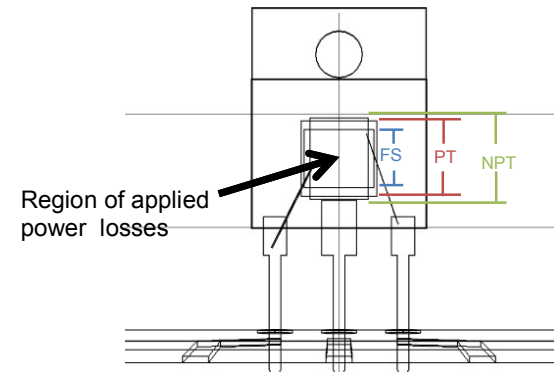

(b)

Figure 9: View of dismounted discrete TO-220 package

Please cite this article as: C. Batunlu, A. Albarbar, Real-time system for monitoring the electro-thermal behaviour of power electronic devices used in boost converters, Microelectronics Reliability (2016), http://dx.doi.org/10.1016/j.microrel.2016.03.033 
Please cite this article as: C. Batunlu, A. Albarbar, Real-time system for monitoring the electro-thermal behaviour of power electronic devices used in boost converters, Microelectronics Reliability (2016), http://dx.doi.org/10.1016/j.microrel.2016.03.033

The heat transfer coefficient $h$ is defined as $5 \mathrm{~W} / \mathrm{m}^{2} \mathrm{~K}$ over the model representing natural convection in heating unit. For higher current applications, heat sink model is built in rear side of the case through mica layer where thermal grease boundary is defined as heat remover boundary condition. Leads are attached by soldering layer on to a PCB via copper channels. Material properties of each layer are listed in Table 3.

Table 3: Material Properties

\begin{tabular}{|c|c|c|c|}
\hline \multirow{2}{*}{ Layer } & \multicolumn{3}{|c|}{ Physical Properties at $\mathbf{2 5}^{\circ} \mathbf{C}$} \\
\cline { 2 - 4 } & $\boldsymbol{p}\left(\mathbf{k g} / \boldsymbol{m}^{3}\right)$ & $\boldsymbol{k}(\boldsymbol{W} / \boldsymbol{m} \boldsymbol{K})$ & $\boldsymbol{c}(\boldsymbol{J} /(\mathbf{k g K})$ \\
\hline Silicon & 2330 & 153 & 703 \\
\hline Copper & 8850 & 398 & 380 \\
\hline Gold & 19300 & 318 & 129 \\
\hline PLCC & 900 & 0.2 & 1700 \\
\hline Steel Alloy & 7850 & 54 & 477 \\
\hline Mica & 2883 & 0.71 & 500 \\
\hline Aluminium & 3010 & 180 & 741 \\
\hline Grease & - & 2 & - \\
\hline
\end{tabular}

\section{RESULTS AND DISCUSSION}

\subsection{Ambient temperature influence:}

Supply voltage to each boost converter was $5 \mathrm{~V}$ with $0.5 \mathrm{~A}$ of input current at $25{ }^{\circ} \mathrm{C}$ ambient temperature. The collector to emitter voltage and current signals are shown in Figure 10.

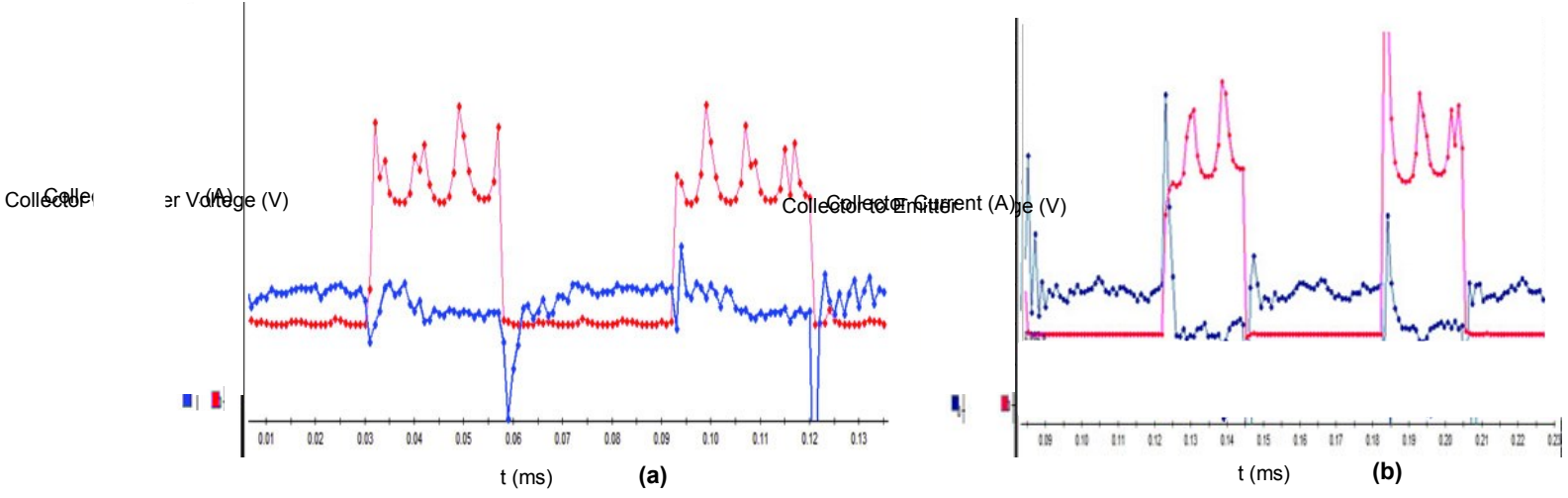

Figure 10: Switching transient of (a) NPT (b) FS IGBTs

The switching transient is much smoother in the FS device due to additional field stop layer while the NPT showed longer transient in the same period. The effect of the longer tail current was also reflected on total power losses where the switches off losses are higher for the NPT, as shown in Figure 11. 
Please cite this article as: C. Batunlu, A. Albarbar, Real-time system for monitoring the electro-thermal behaviour of power electronic devices used in boost converters, Microelectronics Reliability (2016), http://dx.doi.org/10.1016/j.microrel.2016.03.033

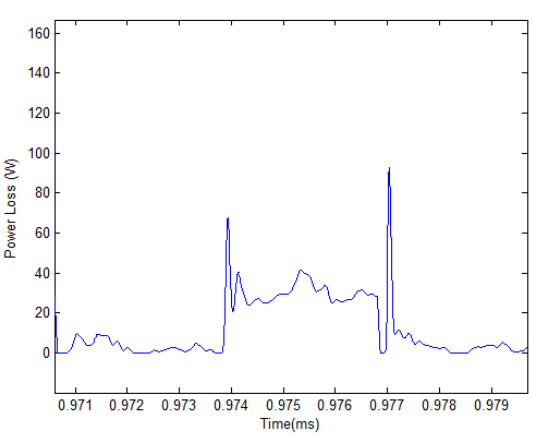

(a)

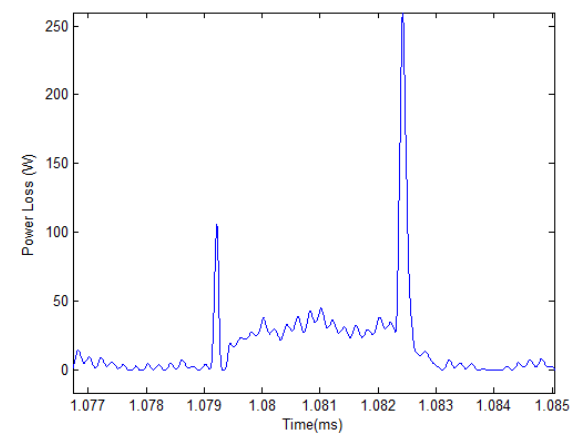

(b)

Figure 11: View of Power loss profile for (a) FS, (b) NPT

On time losses also increased up to $100 \mathrm{~W}$ for NPT where these are only $72 \mathrm{~W}$ for FS device. Ambient temperature effects on IGBTs thermal behaviour, at 25 and $35^{\circ} \mathrm{C}$, are shown in Figures 12 and 13 , respectively.

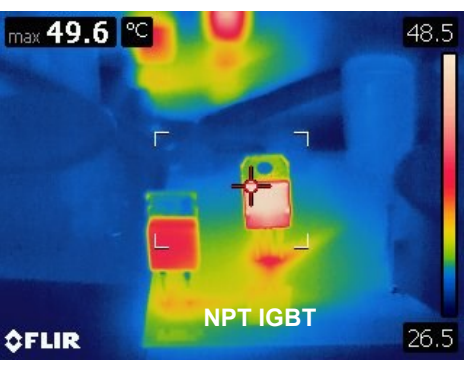

(a)

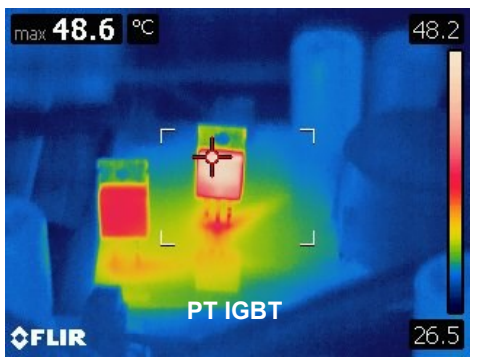

(b)

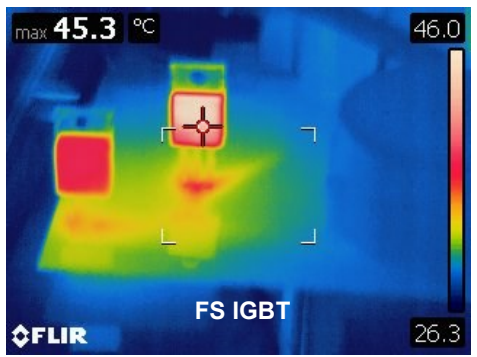

(c)

Figure 12: Thermal camera view (a) NPT, (b) PT, (c) FS at $25^{\circ} \mathrm{C}$ ambient temperature

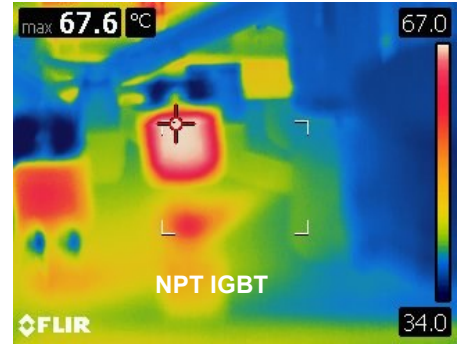

(a)

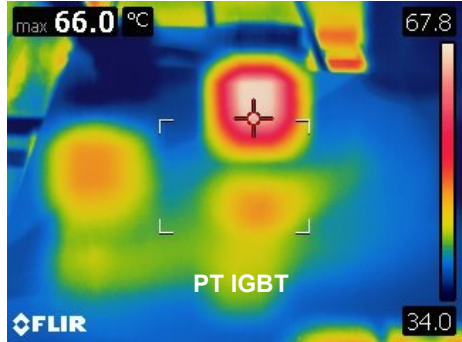

(b)

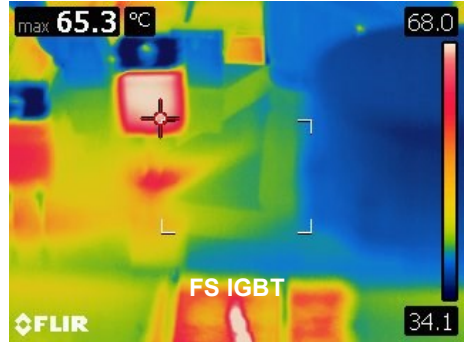

(c)

Figure 13: Thermal camera view (a) NPT, (b) PT, (c) FS at $35^{\circ} \mathrm{C}$ ambient temperature

The FS type exhibits the lowest temperature of $45.3{ }^{\circ} \mathrm{C}$ at both tests compared to the PT and NPT, $48.6{ }^{\circ} \mathrm{C}$ and $49.6{ }^{\circ} \mathrm{C}$. Power loss was use as inputs to the FE model shown in Figure 14.

Please cite this article as: C. Batunlu, A. Albarbar, Real-time system for monitoring the electro-thermal 

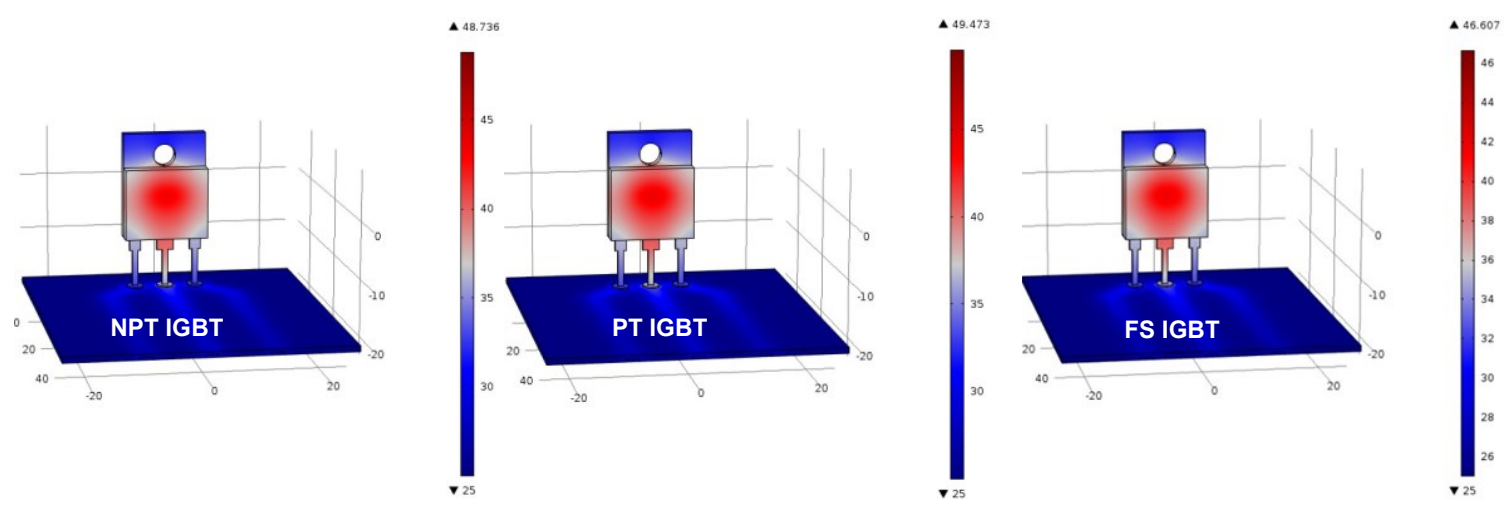

Figure 14: FE model of (a) NPT, (b) PT, (c) FS at $25^{\circ} \mathrm{C}$ ambient temperature

The highest heat was observed around collector lead for all of the IGBTs. The measured temperature for FS and PT show good agreement with the model based calculated figures $(\sim$ $1.2^{\circ} \mathrm{C}$ difference). While the difference was only $0.9^{\circ} \mathrm{C}$ for the NPT type. Experimental and model based transient temperature responses for the FS device is shown in Figure 15 and about $\sim 2^{\circ} \mathrm{C}$ difference were observed.

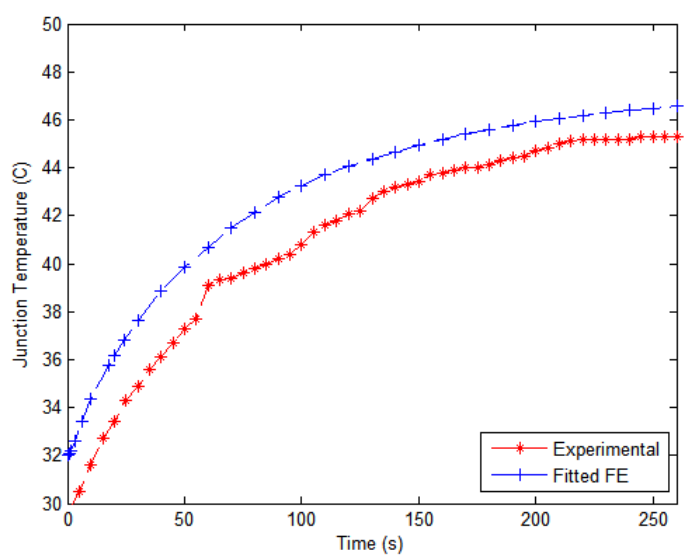

Figure 15: Transient temperature in Simulink based experimental dSPACE model and FE model for FS

\subsection{Influence of Switching Frequency:}

Frequency test results are depicted in Figure 16. Device A (NPT) is subjected to highest temperatures at all frequency ranges where device C (FS) showed less thermal heating especially at higher switching frequencies. 
Please cite this article as: C. Batunlu, A. Albarbar, Real-time system for monitoring the electro-thermal behaviour of power electronic devices used in boost converters, Microelectronics Reliability (2016), http://dx.doi.org/10.1016/j.microrel.2016.03.033

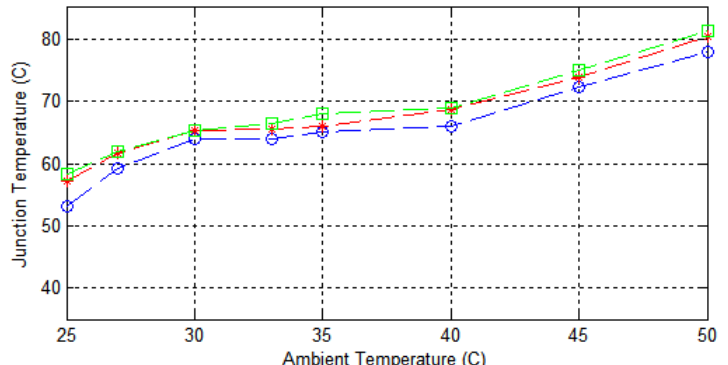

(a) $40 \mathrm{kHz}$

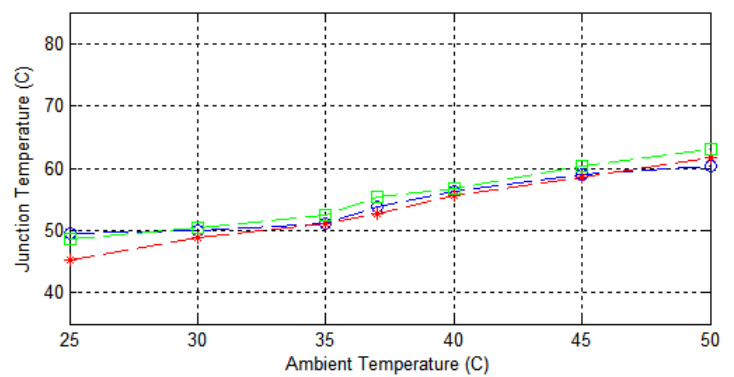

(c) $20 \mathrm{kHz}$

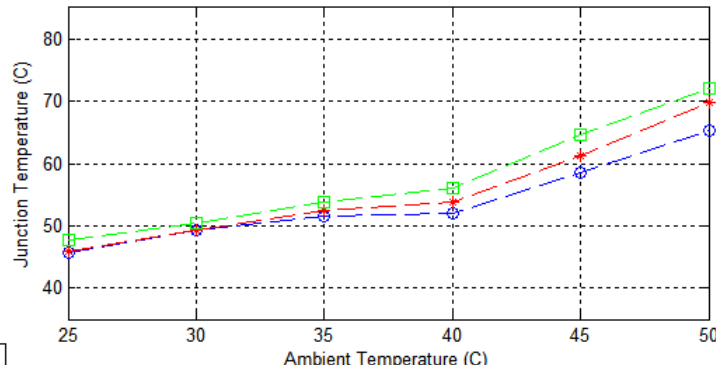

(b) $30 \mathrm{kHz}$

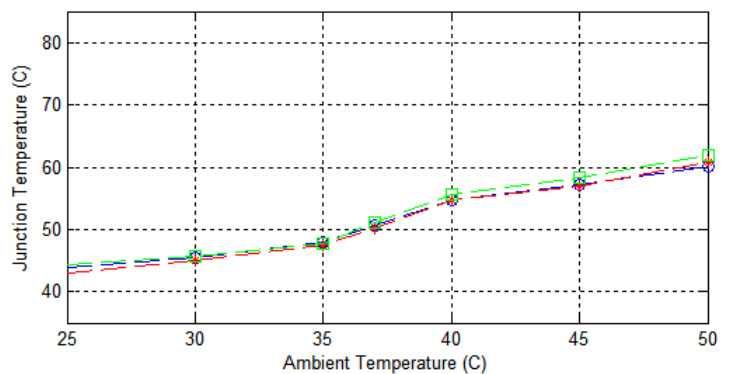

(d) $10 \mathrm{kHz}$

Figure 16: Ambient temperature effect on junction temperature at different switching frequencies

Figure 17 shows results when the devices were run at $20 \mathrm{kHz}$ switching frequency, $25^{\circ} \mathrm{C}$ ambient temperatures and a current of $2 \mathrm{~A}$. The difference in temperature between NPT and FS devices were about $20^{\circ} \mathrm{C}$.

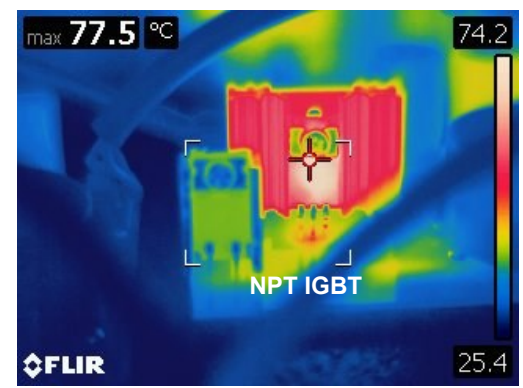

(a)

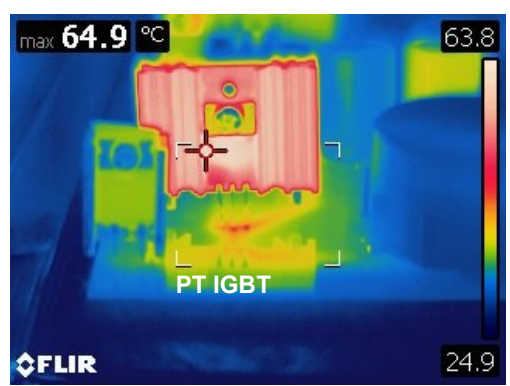

(b)

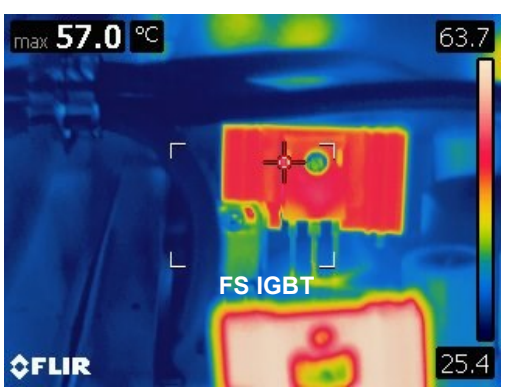

(c)

Figure 17: (a) NPT (b) PT and (c) FS IGBTs at $25^{\circ} \mathrm{C}$ ambient temperature with heat sinks attached

Please cite this article as: C. Batunlu, A. Albarbar, Real-time system for monitoring the electro-thermal behaviour of power electronic devices used in boost converters, Microelectronics Reliability (2016), http://dx.doi.org/10.1016/j.microrel.2016.03.033 
Please cite this article as: C. Batunlu, A. Albarbar, Real-time system for monitoring the electro-thermal behaviour of power electronic devices used in boost converters, Microelectronics Reliability (2016), http://dx.doi.org/10.1016/j.microrel.2016.03.033
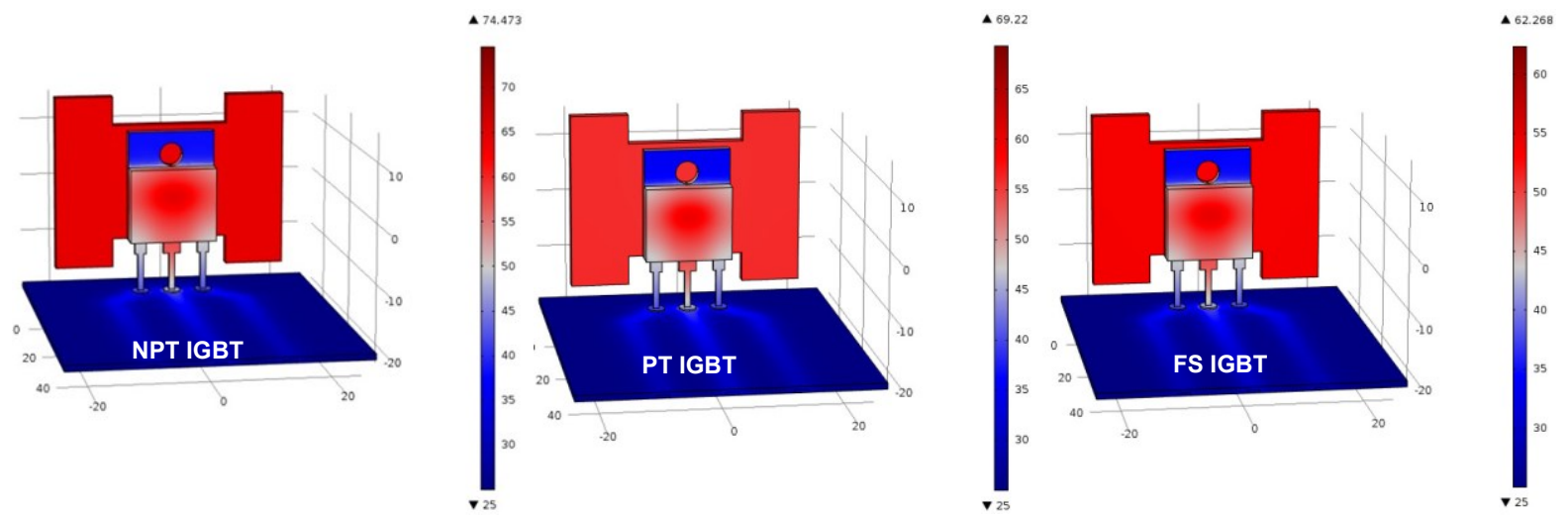

Figure 18: FE model of (a) NPT, (b) PT, (c) FS at $25^{\circ} \mathrm{C}$ ambient temperature with attached heatsinks

Accuracy of the model has decreased by approximately 3.7\% when higher current was drawn, see Figure 18. For NPT, the steady state temperature is $3.2^{\circ} \mathrm{C}$ lower with the FE model, which is $74.4{ }^{\circ} \mathrm{C}$, compared to the $77.6{ }^{\circ} \mathrm{C}$ of experimental result. The approximation in the physical shape of the heat sink and used thermal grease layer may cause the minor discrepancy. Higher currents may caused change in the material properties of the device. Experimental and model based NPT transient temperature responses are shown in Figure 19.

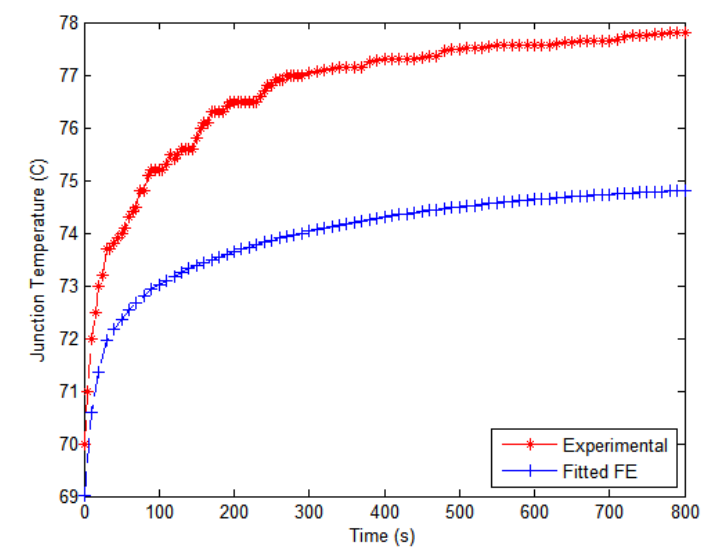

Figure 19: Transient temperature in Simulink based experimental dSPACE model and FE model for NPT

\section{3: Effects of Load Variation}

Thermal behaviour of the examined devices due to load variations are shown in Figure 20. As anticipated, the FS device was affected much less than the other two devices by load variation. However, it's worth to mention temperature changes of the PT device was seen as less dynamic (lowest slope). 
Please cite this article as: C. Batunlu, A. Albarbar, Real-time system for monitoring the electro-thermal behaviour of power electronic devices used in boost converters, Microelectronics Reliability (2016), http://dx.doi.org/10.1016/j.microrel.2016.03.033

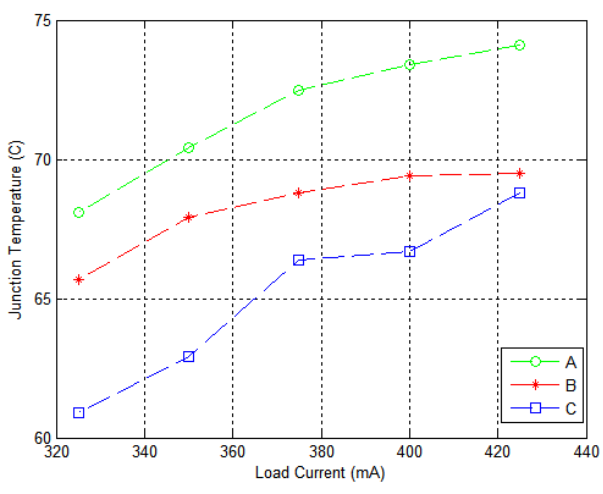

(a)

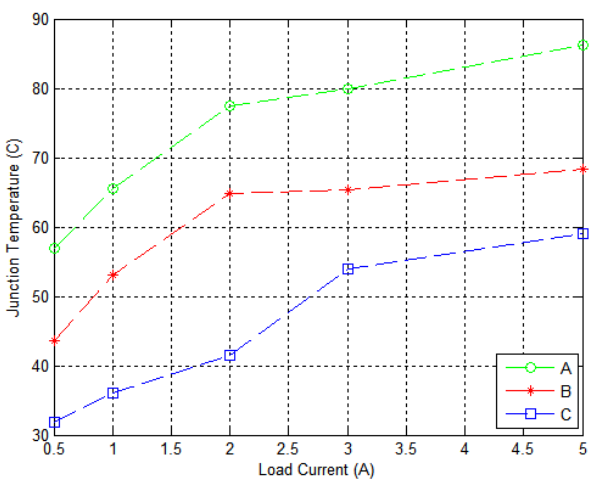

(b)

Figure 20: Junction temperature at various load characteristics (a) without (b) with heat sink

Efficiency for each boost converter module were also affected by the performance of their switching elements as shown Figure 21 . The ambient temperature was kept at $30^{\circ} \mathrm{C}$ and the operating switching frequency was set to $20 \mathrm{kHz}$.

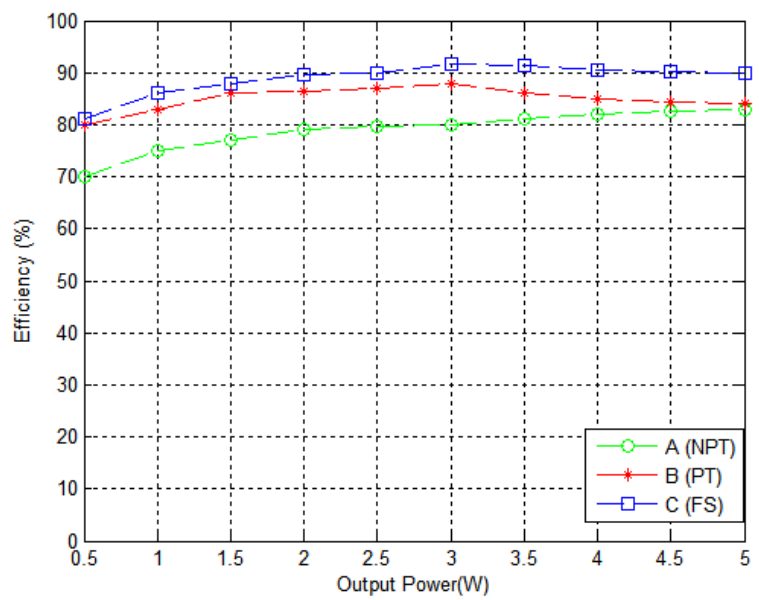

Figure 21: Output power efficiency of Boost Converter among each device

The FS device was found to be the most efficient one in all of the cases. For example, the FS efficiency was about $92 \%$ while it was only $80 \%$ for NPT when the output power was $3 \mathrm{~W}$.

\section{CONCLUSION}

Powerful and inexpensive system to monitor the electro thermal characteristics of IGBTs used in boost converters was developed. The system determines IGBTs temperatures and heat distributions based on current and voltage measurements and embedded models. System's performance was validated via a series of experiments using accurate thermal imaging. All the effort was made to assure devices were tested under same environmental and electric loading conditions. Effects of switching frequency were also studied and devices were operated with 
Please cite this article as: C. Batunlu, A. Albarbar, Real-time system for monitoring the electro-thermal behaviour of power electronic devices used in boost converters, Microelectronics Reliability (2016), http://dx.doi.org/10.1016/j.microrel.2016.03.033

and without heat sinks. Thermal variations are found as not linear and the FS device showed consistent behaviour in all cases. PT device had better electro thermal performance compared with NPT. The reason for that may be the higher NPT conduction losses as temperature increases due to its positive temperature coefficient. For the FS, the presence of field stop layer accelerates the majority carrier recombination during the turn-off intervals and lower saturation voltage drop; hence its tail current is much smaller than both NPT and PT devices. This leads lower switching losses and temperature characteristics. Regarding to overall performance of modelling approach, about $3{ }^{\circ} \mathrm{C}$ temperature difference was observed for FS and PT as the current level increased from 0.5 to $2 \mathrm{~A}$. Overall, model based predicted results were in good agreement with the empirical data.

\section{References}

[1] A. Alessandria, L. Fragapane, and G. Morale, "Design considerations on field-stop layer processing in a trench-gate IGBT," in 13th European Conference on Power Electronics and Applications, 2009. EPE '09, 2009, pp. 1-6.

[2] R. Chibante, A. Araujo, and A. Carvalho, "A new physics based SPICE model for NPT IGBTs," in The 29th Annual Conference of the IEEE Industrial Electronics Society, 2003. IECON '03, 2003, vol. 2, pp. 11561161 Vol.2.

[3] R. Chibante, A. Araujo, and A. Carvalho, "A FEM punch-through IGBT model using an efficient parameter extraction method," in 31st Annual Conference of IEEE Industrial Electronics Society, 2005. IECON 2005, 2005, p. 6 pp.-.

[4] J. Takaishi, S. Harada, M. Tsukuda, and I. Omura, "Structure oriented compact model for advanced trench IGBTs without fitting parameters for extreme condition: Part II," Microelectron. Reliab., vol. 54, no. 9-10, pp. 1891-1896, September 2014.

[5] C. Ronsisvalle, H. Fischer, K. S. Park, C. Abbate, G. Busatto, A. Sanseverino, and F. Velardi, "High frequency capacitive behavior of field stop trench gate igbts operating in short circuit," in 2013 Twenty-Eighth Annual IEEE Applied Power Electronics Conference and Exposition (APEC), 2013, pp. 183-188.

[6] D. Zhou, F. Blaabjerg, M. Lau, and M. Tonnes, "Thermal cycling overview of multi-megawatt two-level wind power converter at full grid code operation," IEEJ J. Ind. Appl., vol. 2, no. 4, pp. 173-182, 2013.

[7] Y. Tang, B. Wang, M. Chen, and B. Liu, "Simulation model and parameter extraction of Field-Stop (FS) IGBT,” Microelectron. Reliab., vol. 52, no. 12, pp. 2920-2931, December 2012.

[8] P. Lefranc, D. Planson, H. Morel, and D. Bergogne, "Analysis of the dynamic avalanche of punch through insulated gate bipolar transistor (PT-IGBT)," Solid-State Electron., vol. 53, no. 9, pp. 944-954, September 2009.

[9] L. Benbahouche, A. Merabet, and A. Zegadi, "An improved understanding of IGBT behavior under thermal stress," in 26th International Conference on Microelectronics, 2008. MIEL 2008, 2008, pp. 189-192.

[10] C. Batunlu, A. Albarbar, "A technique for mitigating thermal stress and extending life cycle of power electronic converters used for wind turbines," Electronics, vol. 4, no. 4, pp. 947-968, Nov. 2015.

[11] A. de Pádua Finazzi, G. B. de Lima, L. C. de Freitas, E. A. A. Coelho, V. J. Farias, and L. C. G. Freitas, "Proposal for preprogrammed control applied to a current-sensorless PFC boost converter," Microprocess. Microsyst., vol. 38, no. 5, pp. 443-450, July 2014.

[12] A. Khosroshahi, M. Abapour, and M. Sabahi, "Reliability evaluation of conventional and interleaved dc-dc boost converters," IEEE Trans. Power Electron., vol. 30, no. 10, pp. 5821-5828, October 2015.

[13] A. Blinov, D. Vinnikov, and T. Jalakas, "Loss Calculation Methods of Half-Bridge Square-Wave Inverters," Electron. Electr. Eng., vol. 113, no. 7, Sep. 2011.

[14] W. Rui, W. Jialiang, H. Jian, C. Zhongyuan, W. Quanqing, J. Na, and W. Chenghao, “A power loss calculation method of IGBT three-phase SPWM converter," in 2012 Second International Conference on Intelligent System Design and Engineering Application (ISDEA), 2012, pp. 1180-1183.

Please cite this article as: C. Batunlu, A. Albarbar, Real-time system for monitoring the electro-thermal behaviour of power electronic devices used in boost converters, Microelectronics Reliability (2016), http://dx.doi.org/10.1016/j.microrel.2016.03.033 
Please cite this article as: C. Batunlu, A. Albarbar, Real-time system for monitoring the electro-thermal behaviour of power electronic devices used in boost converters, Microelectronics Reliability (2016), http://dx.doi.org/10.1016/j.microrel.2016.03.033

[15] V. Ivakhno, V. V. Zamaruiev, and O. Ilina, "Estimation of semiconductor switching losses under hard switching using matlab/simulink subsystem," Electr. Control Commun. Eng., vol. 2, no. 1, pp. 20-26, 2013.

[16] Z. Zhou, M. S. Kanniche, S. G. Butcup, and P. Igic, "High-speed electro-thermal simulation model of inverter power modules for hybrid vehicles," IET Electr. Power Appl., vol. 5, no. 8, pp. 636-643, Sep. 2011.

[17] K. Ma and F. Blaabjerg, "The Impact of Power switching devices on the thermal performance of a $10 \mathrm{mw}$ wind power npc converter," Energies, vol. 5, no. 7, pp. 2559-2577, Jul. 2012.

[18] C. Batunlu, A. Albarbar 'Towards more reliable renewable power systems-thermal performance evaluation of dc/dc boost converters switching devices' International Journal of Power Electronics and Drive Systems (IJPEDS), 6 (4) pp 876-887, 2015.

[19] R. Pittini, S. D’Arco, M. Hernes, and A. Petterteig, "Thermal stress analysis of IGBT modules in VSCs for PMSG in large offshore Wind Energy Conversion Systems," in Proceedings of the 2011-14th European Conference on Power Electronics and Applications (EPE 2011), 2011, pp. 1-10.

[20] T. Kim, M. Jang, and V. G. Agelidis, "Practical implementation of a silicon carbide-based $300 \mathrm{kHz}, 1.2 \mathrm{~kW}$ hard-switching boost-converter and comparative thermal performance evaluation," IET Power Electron., vol. 8, no. 3, pp. 333-341, 2015.

[21] Thermal imaging camera FLIR T440, https:/www.reichelt.com/Thermal-Imaging-Cameras/FLIRT440/3/index.html?\&ACTION=3\&LA=3\&ARTICLE=120623\&GROUPID=5910. Accessed Feb-2016.

Please cite this article as: C. Batunlu, A. Albarbar, Real-time system for monitoring the electro-thermal 